\title{
Avaliação dos determinantes de endividamento público dos Entes Subnacionais Brasileiros
}

\author{
Assessment of the determinants of public debt of \\ Brazilian Sub-National Entities
}

\author{
Francisco Itamar Cassimiro ${ }^{1}$ \\ Roberto Sérgio do Nascimento ${ }^{2}$ \\ Ricardo Viotto ${ }^{3}$
}

\section{RESUMO}

A dívida pública integra a realidade brasileira desde o início do século XX. $\mathrm{O}$ desequilíbrio orçamentário constitui condição básica para a ocorrência do endividamento público, o que acarreta descompasso no fluxo financeiro das entradas e saídas dos recursos públicos. Com base em estudos que avaliaram a existência de determinantes do endividamento, essa pesquisa teve como objetivo verificar a influência da despesa com pessoal (Depes), de liquidez (LIQ) e do investimento (INV) sobre o endividamento dos estados brasileiros. A pesquisa está classificada como descritiva, quantitativa e documental, sendo a população constituída pelos 26 estados membros e o Distrito Federal, tendo por base o ano de 2016, ano em que o Governo Federal editou a EC 156/2016 destinada à repactuação das dívidas dos entes subnacionais. Mediante o uso da técnica de regressão linear múltipla, concluiu-se que duas (Depes e LIQ) das três variáveis apresentaram significância, ou seja, influenciam o endividamento dos estados. A variável INV não apresentou significância, contrariando a hipótese $\mathrm{H} 1$ de que os investimentos no país, em sua maioria, decorrem da realização de operações de crédito contratadas. Explicou-se que o resultado poderia estar as-

Contador (UFC) e administrador de empresas (Unifametro). E-mail: itamarcassimiro2015@gmail.com 2 Doutor em Contabilidade, professor da Universidade Federal do Ceará (UFC), auditor do Tribunal de
Contas da União (TCU), Secretaria de Estratégias para o Combate à Fraude e Corrupção (Seccor). E-mail: robertosn@tcu.gov.br

3 Advogado, especialista em Direito Processual Civil, mestrando em Administração e Controladoria (UFC). E-mail: ricardoviotto@yahoo.com 
sociado a teoria dos ciclos políticos, na qual os investimentos crescem no período pré-eleitoral e decrescem no ano seguinte às eleições. Apresentou como fatores limitadores a falta de divulgação dos dados até a conclusão da pesquisa do Estado do RN.

Palavras-Chave: Dívida Pública. Determinantes. Estados Federados. Estatística Multivariada.

\section{ABSTRACT}

Public debt has been part of the Brazilian reality since the beginning of the 20th century. The budgetary imbalance is a basic condition for the occurrence of public indebtedness, which causes a mismatch in the financial flow of inflows and outflows of public resources. Based on studies that assessed the existence of determinants of indebtedness, this research aimed to verify the influence of personnel expenses (DEPES), liquidity (LIQ) and investment (INV) on the indebtedness of Brazilian states. The research is classified as descriptive, quantitative and documentary, with the population consisting of the 26 member states and the Federal District, based on the year 2016, the year in which the Federal Government introduced a new law aimed at renegotiating the debts of subnational entities. Through the use of the multiple linear regression technique, it was concluded that two (DEPES and LIQ) of the three variables showed significance, that is, they influence the indebtedness of the States. The variable INV was not significant, contradicting hypothesis $\mathrm{H} 1$ that investments in the country, for the most part, result from contracted credit operations. It was explained that the result could be associated with the theory of political cycles, in which investments grow in the pre-electoral period and describe in the year following the elections.

Keywords: Public Debt. Determinates. Federated States. Multivariate Statistics.

Recebido: 01-10-2020

Aprovado: 25-10-2020 


\section{INTRODUÇÃO}

O desequilíbrio fiscal associado à necessidade de ajuste das contas públicas tem dominado o debate econômico já há algum tempo nos três níveis de governo e se intensifica em momentos de crises financeiras. No âmbito federal, a escalada da dívida pública foi um dos motivos alegados para a determinação constitucional inédita de limitar o crescimento dos gastos públicos (EC n 95/2016), bem como o encaminhamento de reformas fundamentais para a sustentabilidade fiscal de longo prazo, como a da previdência (BRASIL, 2016).

Para Pereira (2002), o endividamento público deriva de o ente público realizar despesas superiores às suas receitas, o que origina o conceito de déficit. Esse descompasso entre receitas e despesas somente é possível face uma das seguintes condições: emissão de dinheiro para fazer frente às despesas, no caso da União, ou, no caso de qualquer dos demais entes federados, a contratação de operações de crédito. $\mathrm{O}$ endividamento seria então uma das formas de financiamento do desequilíbrio fiscal.

Dados públicos divulgados pelo Tesouro Transparente ${ }^{4}$ demonstram que a dívida consolidada dos estados chegou em 2018 à cifra de R\$ 872.485.539.792,20, sendo a maioria - 77,9\% - representada por empréstimos e financiamentos internos, seguida por operações externas $(12,3 \%)$. Dentre os estados mais endividados, encontram-se o Rio de Janeiro, com $262,92 \%$ da RCL, seguido pelo Rio Grande do Sul (222,90\%), e os menos endividados, Amapá (1,25\%) e Pará (13,31\%). Diferentemente, os municípios possuem situação fiscal mais grave, devido ao número de entes que superaram o limite fiscal permitido, com percentuais que chegam a $449,67 \%$ da RCL, como é o caso de Parnaguá-PI.

Linhares et al. (2013) complementam ao afirmar que o endividamento do setor público, a exemplo da própria União com a extraordinária quantia de R \$ 5.764.560.885.784,74 (dados de 2018), é verificado quando

4 Disponível em: www.tesourotransparente.gov.br 
as receitas não são suficientes para cobrir as despesas, sendo a palavra que predominou por muitos anos no cenário da Administração Pública foi a de déficit. Contudo, a partir da Constituição Federal de 1988, mecanismos com propostas eficientes vêm paulatinamente sendo criados e utilizados para reverter esta situação, como a chamada Regra de Ouro contida no art. 167, inc. III da CF/88 (BRASIL, 1988), ratificada pelo art. 12, $\S 2^{\circ}$ da Lei de Responsabilidade Fiscal-LRF (Brasil, 2000). Tais alterações legislativas vieram no compasso de outra lei anterior - no ano de 1995 - a chamada Lei Camata LC 82/1995 que deu origem posterior à LC Camata II (LC 96/99) (Brasil, 1995; Brasil, 1999). Isto é, as alterações legislativas puseram em debate a importante questão da sustentabilidade do endividamento público brasileiro (CALDEIRA et al., 2016).

A criação da LRF (BRASIL, 2000) pode ser citada como um dos principais mecanismos constantes da legislação brasileira, na esteira de outros de origem internacional sob a mesma temática (Budget Enforcement Act dos EUA de 1990, Tratados de Maastricht da União Europeia de 1992, Lei de Responsabilidade Fiscal na Nova Zelândia de 1994, Código de Boas Práticas para a Transparência Fiscal do FMI e Manual de Transparência Fiscal de 2007). A lei brasileira é bem diversa destes comandos normativos, visto ser uma verdadeira composição das leis de ajustes que a antecederam, com ênfase em temas como o acompanhamento da dívida e endividamento público, entre outros.

Para Queiroz et al. (2018), a dívida pública está relacionada ao desequilíbrio do fluxo fiscal das entradas, provenientes das receitas tributárias, e das saídas de recursos, advindos dos gastos do governo, o que Tabosa, Ferreira e Simonasse (2011) conceituaram como restrição orçamentária governamental. Quando o total das saídas excede o montante das entradas se tem o déficit orçamentário, e isto atua diretamente na criação do fenômeno da dívida pública pois compõe fonte de recurso alternativa para suprir a condição de desequilíbrio orçamentário. 
Em 2016, houve alguns acontecimentos relacionados a esses desequilíbrios, estando um deles ligado aos esforços dos entes subnacionais para que houvesse modificação na métrica de cálculo relativo à contabilização dos juros. Como resultado, os interessados obtiveram liminar que autorizava o pagamento de suas respectivas dívidas através de juros simples e, em seguida, no mesmo ano, houve a promulgação da LC 156/2016 que estabeleceu o Plano de Auxílio aos Estados e ao Distrito Federal e medidas de estímulo ao reequilíbrio fiscal (BRASIL, 2016).

Outro importante marco contra o endividamento crescente brasileiro consistiu na aprovação da EC 95/2016, que se tornou bastante polêmica ao propor o congelamento de gastos com relação ao ano anterior, atualizado pela inflação, durante o período de 20 anos (BRASIL, 2016). A medida se destinou a todas as esferas administrativas, sendo considerada por seus defensores como uma forma de reequilíbrio das contas públicas e retomada do crescimento econômico. De acordo com Miranda et al. (2018), todos esses dispositivos foram criados diante das péssimas situações das gestões nos últimos anos, sobretudo as estaduais.

Dito isso, o presente artigo se encontra organizado, além desta introdução, em referencial com abordagem dos fundamentos teóricos que circundam o endividamento público no país, revisão da literatura acerca de variáveis que podem alavancar a dívida e o endividamento público, metodologia onde se busca detalhar a estrutura de cálculo utilizada para fins de análise dos resultados alcançados, seguida das análises e discussão dos resultados, bem como as conclusões a que se chegou o estudo.

\section{REFERENCIAL TEÓRICO}

O interesse pelo acompanhamento da dívida pública dos entes subnacionais (estados e municípios) é um assunto relativamente recente no cenário brasileiro. Pode-se dizer, inclusive, que assumiu projeção nacional após o advento da LC 101/2000 (LRF) (BRASIL, 2000). Esta, por sua 
vez, foi fruto da $\mathrm{CF} / 88$, que continha determinação para elaboração de lei própria que trataria da temática, dentre outros assuntos.

Conquanto o monitoramento desses passivos seja considerado relativamente atual, importa destacar que o tema vem sendo considerado preocupante por parte da União, sobretudo em virtude dos estoques da dívida do país, razão pela qual tem despertado idêntico cuidado em relação aos entes subnacionais. $\mathrm{O}$ desequilíbrio financeiro é considerado grave quando a receita corrente líquida (RCL) anual do Estado é menor do que a dívida consolidada ao final do último exercício; o somatório das suas despesas com pessoal, juros e amortizações é igual ou maior do que 70\% da RCL e o valor total das obrigações supera as disponibilidades de caixa consoante à LC 159/2017 (BRASIL, 2017).

A dívida pública integra a realidade do país desde a formação do Estado brasileiro em decorrência dos sucessivos déficits orçamentários oriundos de ações realizadas no passado (Blanchard, 2011). Há quase uma unanimidade em atribuí-la como resultado dos ciclos desenvolvimentistas desde o início do século XX. Os governos republicanos que nele se iniciaram observaram a extraordinária carência brasileira por obras de infraestrutura de grande vulto (hidrelétricas, portos, aeroportos, rodovias etc.) em áreas vitais (transporte, indústrias básicas, energia etc.), além de insumos básicos necessários para o processo de industrialização que florescia à época. Em função destes aspectos, o endividamento público pode ser diagnosticado como resultante do processo de aumento da intervenção do Estado na economia, substituição do modelo de importações existente e proteção do mercado local (GIAMBIAGI; ALÉM, 2016).

Diferentemente de países como os EUA, que possuíam mercado de capitais em ascensão, os esforços de investimento público brasileiros foram calcados no tripé composto pelos capitais estatal, multinacional e privado nacional. O estatal gozava do status de principal fonte para promoção dos meios necessários com a emissão de títulos da dívida pública junto ao mercado interno ou externo. 
Assim, a busca constante de recursos por parte do Estado brasileiro, associada à tendência intervencionista-nacionalista vigente que se contrapunha à liberal de vários países do entorno, moldou a forma do endividamento brasileiro. De acordo com Giambiagi e Além (2016), o descontrole fiscal observado tinha como objetivo solucionar problemas locais relacionados à balança de pagamentos, ao projeto de industrialização acelerado frente a uma economia atrasada e a decisão pelo controle das atividades de empresas estrangeiras, principalmente no setor de utilidades públicas e exploração de recursos naturais.

Embora as causas que propiciaram o endividamento nacional não possam ser simplesmente trasladas aos demais entes federados, no âmbito de estados e municípios, as renegociações dos passivos contraídos nas últimas décadas evidenciaram relaxamento na condução fiscal, produzindo comportamento de desequilíbrio das dívidas administradas.

A linha ascendente do endividamento dos entes subnacionais suscitou importante questão de risco moral referente a uma espiral de ordem financeira sem solução. Suspeitava-se da existência de "incentivo" - mesmo que velado - no presente para aumento dos passivos contraídos, apoiado na crença de um socorro financeiro no futuro. Em oposição a esta realidade considerada negativa, Mello e Slomski (2009) observaram que houve a construção de mecanismos ao longo dos anos para o aperfeiçoamento do controle das finanças estaduais, eis que novos instrumentos surgiriam e os antigos seriam melhorados.

Independentemente da origem ou da configuração da dívida pública brasileira, o certo é que o processo de redemocratização do país em 1988 - que deu origem posterior à LRF - permitiu à União repensar seu papel como agente propulsor das finanças públicas federais, estaduais e municipais. A LRF nasceu, então, sob a ótica de que o Estado - de forma distinta do que se vinha ocorrendo - deveria exercer uma administração financeira pública de qualidade e demonstrar equilíbrio em suas contas, gastando e 
investindo menos do que se arrecadava (Piccoli; Jeriszurki, 2018).

Antes propriamente da LRF, o desequilíbrio fiscal já era considerado um dos principais problemas macroeconômicos. A LC 101/2000 foi considerada divisor de águas, na medida em que passou a evidenciar por meio de relatórios a falta de sustentabilidade das contas públicas da União e dos demais entes federados.

Em nível estadual e municipal, o acompanhamento pari passu da situação fiscal permitiu constatar realidades até então não conhecidas do grande público. Uma delas seria a inexistência de controles efetivos das finanças públicas por parte dos entes subnacionais, tanto por parte de quem tinha a responsabilidade direta de realizá-los - a própria administração -, como quem dispunha de atribuição de ordem constitucional, no caso os responsáveis pelo Sistema de Controle Interno e Externo.

Até recentemente, o acompanhamento da trajetória da dívida pública se dava quase que exclusivamente com base nos registros contábeis oriundos do balanço patrimonial elaborado a partir da Lei $n^{\circ} 4320 / 64$ (BRASIL, 1964). As informações nele contidas, além de serem pouco atualizadas, visto que não atendiam ao princípio da competência, tampouco se encontravam alinhadas às Normas Internacionais de Contabilidade Aplicadas ao Setor Público (IPSAS, acrônimo em inglês). Tal assertiva é corroborada pelo trabalho de Galdino, Moura e Cunha (2014) que encontraram evidências acerca da subavaliação da dívida flutuante em torno de $52 \%$ pela simples adoção do enfoque patrimonial definido pelo processo de convergência da contabilidade pública às normas internacionais.

Toda a informação da dívida pública que incluía os juros respectivos (KORAMA, 2014) era apresentada tendo como referência dois macros agregados: a chamada dívida flutuante, de curto prazo, e a fundada ou consolidada, de longo prazo. O primeiro compreendia as obrigações realmente assumidas pelo Estado, a título de empréstimo, sendo considerada como dívida de curto prazo, seja para investimentos e financiamentos de 
serviços públicos, ou para atender às necessidades momentâneas de caixa. $\mathrm{O}$ segundo se referia às dívidas com prazo superior a 12 (doze) meses, significando o conjunto de débitos contraídos pelo Estado para atender a desequilíbrios orçamentários, financeiros de obras e serviços públicos, ou ainda, para o reconhecimento de obrigações legais e tributárias perante o fisco e terceiros (BRASIL, 1964).

Ante o baixo nível de accountability e transparência do setor público, a LRF se destacou ao ampliar sensivelmente o escopo informacional de temas relacionados às finanças públicas (planejamento, receitas, despesas, gestão patrimonial, transparência, controle e fiscalização etc.). Além disso, inaugurou uma verdadeira "intervenção legislativa" da União junto a estados e municípios, impondo a estes as mesmas regras que ela (União) passaria a empregar, o que proporcionou um considerável avanço legislativo da contabilidade pública no país.

Assim, a homogeneidade e a modernização das regras de administração financeira adotadas posicionaram os diversos entes federados num patamar mais elevado, diminuindo a assimetria de procedimentos fiscais que existia entre as regiões. Soares et al. (2012) observaram que o endividamento público podia, inclusive, ser relacionado a fatores culturais, à sociedade e à sua dinâmica político-econômica, tendo em vista a forma como as necessidades coletivas eram satisfeitas, confirmando, de certa maneira, a constatação da discrepância de regras fiscais país afora.

A melhora significativa informacional do endividamento do Estado ocorrida, tanto em termos qualitativos quanto quantitativos, foi outro aspecto inegável e um dos pontos chave da LRF. No tocante ao aspecto qualitativo, diversificaram-se as variáveis de mensuração do endividamento a serem utilizadas (dívida consolidada bruta e líquida, inclusão de informações sobre refinanciamento/amortização no balanço orçamentário, contratação de operações de créditos, inclusive do tipo antecipação da receita orçamentária, renúncia fiscal etc.) por parte dos stakeholders. Em relação à variável quan- 
titativa, o disclosure público foi sobremaneira impactado a partir do número de relatórios divulgados e do lapso temporal com que os dados passaram a ser publicizados (bimestral e quadrimestral) (BRASIL, 2000).

Logo, houve um ganho real tanto nos mecanismos de accountability, quanto nos de transparência (arts. 48 e 49, 56 da LRF) (BRASIL, 2000). A divulgação sistematizada e rotineira de vários grupos de resultados fiscais foi, sem sombra de dúvida, um dos aspectos mais relevantes da LRF.

De forma distinta dos relatórios contábeis - em geral publicados somente ao final do exercício -, a lei fiscal brasileira inaugurou a divulgação bimestral (Relatório Resumido da Execução Orçamentária-RREO) e quadrimestral (Relatório de Gestão Fiscal-RGF) dos dados fiscais. O intento da adoção de prazos mais exíguos, quando comparados ao padrão societário e da contabilidade pública do país, residiu na possibilidade de corrigir as metas projetadas incluídas nos instrumentos de planejamento público (PPA, LDO e LOA) de forma mais tempestiva.

Inclusive, a preocupação com o endividamento público passou a ser tão relevante para o contexto das finanças públicas brasileiras que até se alterou o prazo de cômputo das operações de crédito como dívida consolidada. Mesmo aquelas contraídas com prazo inferior a 12 meses deveriam nela ser incluídas para efeitos fiscais (LRF, art. 29, inc. V, $\S 3^{\circ}$ ) (BRASIL, 2000), o que tornou a lei fiscal mais restritiva que a lei contábil.

A partir da LRF, criou-se ambiente político para a promulgação de outra lei (Lei de Crimes Fiscais - 10.028/2000) que possibilitou a punição dos chamados ilícitos fiscais em relação aos administradores públicos que viessem a descumprir os limites e determinações contidos na LRF (BRASIL, 2000). Tal regramento foi considerado em consonância com o disciplinamento contido no art. $\S 1^{\circ}$ do art. $1^{\circ}$ da LC 101/2000 acerca da responsabilidade dos agentes públicos com gestão fiscal e ações a ela inerentes: planejamento, transparência, prevenção de risco e correção de desvios capazes de afetar o equilíbrio das contas públicas (BRASIL, 2000). 
A LRF em si não determinou limites para o endividamento público. Recepcionou o tema e o encaminhou à regulamentação por parte do Senado Federal, que o fez por intermédio das Resoluções n ${ }^{\circ} 40$ e 43/2001 (Brasil, 2001). Tais normativos definiram conceitos para dívida pública (consolidada, mobiliária e consolidada líquida), limites de endividamento para estados, DF (200\% RCL) e municípios (120\% RCL), além de condições para contratação de operações de crédito interna e externas por parte dos entes subnacionais.

Deve-se entender de forma pontual que o endividamento, por si só, não é considerado algo ruim para as finanças públicas, inclusive, no curto prazo, a dívida pública é até um fator de estímulo à demanda agregada e de expansão da atividade econômica. De acordo com Rezende (2001), no longo prazo, a situação se inverte, ocupando espaço que seria destinado à formação de capital, reduzindo investimentos e conduzindo a um menor crescimento econômico.

No país, o endividamento exerce um forte papel social, na medida em que é responsável pelos meios de criação da estrutura pública necessária à promoção de boa parte dos bens e serviços postos à disposição da sociedade (portos, aeroportos, estradas, escolas, hospitais, ferrovias etc.). Em regra geral, os entes públicos não conseguem atender de imediato as reivindicações da comunidade, principalmente àquelas que envolvem investimento com alto valor agregado, razão pela qual a captação de recursos ainda hoje se faz necessária e imprescindível à realização de investimentos.

Daí porque a existência do endividamento público deve ser compreendida como a forma que o Estado possui para financiar suas restrições orçamentárias e assim atender às necessidades coletivas. Dito de outra forma: as dívidas interna e externa são, na verdade, o esforço do governo em regularizar a prestação dos serviços públicos cabíveis à sociedade (LIMA, 2011) como resposta às falhas de mercado (GIAMBIAGI; ALÉM, 2011) ou em decorrência das falhas de governo (VARGAS, 2011). 
Este pensamento é sustentado sob o argumento de que a função da Administração Pública é maximizar o bem-estar social, razão pela qual é possível deduzir a existência de uma verdadeira relação intrínseca entre endividamento público e as funções de governo (alocativa, distributiva e estabilizadora) defendidas por Musgrave (1973). Corroborando esta assertiva, Araújo, Monteiro e Cavalcante (2010) defendem que a análise do gasto público é fundamental e está relacionada com o crescimento econômico e à estrutura física, que contribuem para o crescimento do PIB, o que não é percebido pelos gastos administrativos de custeio.

Contudo, Pereira et al. (2016) alertam para a existência continuada de déficits orçamentários. Segundo os autores, esse comportamento poderá indicar outras questões na condução da política orçamentária, razão pela qual a fixação e a verificação periódica de indicadores fiscais se fazem necessárias. Uma possível solução para a questão seria a adoção de políticas fiscais consistentes que possuem papel contracíclico e podem atenuar recessões e superaquecimentos econômicos externos (OLIVEIRA, 2012).

$\mathrm{Na}$ esteira de que a LRF desempenharia importante missão na contenção do déficit público e do endividamento, Macedo e Corbari (2009) propuseram o cumprimento intertemporal de metas de resultado fiscal relacionadas ao endividamento. Outros estudos seguiram idêntico caminho ao buscar uma possível correlação das ações propostas na lei fiscal com os resultados operados notadamente quanto ao endividamento público.

Mello e Dalchiavon (2012) analisaram se houve a redução de endividamento e o cumprimento dos limites da dívida pública em 81 municípios potiguares. Como resultado, observaram evidências do controle do avanço do endividamento pós LRF, porém, ao compararem os resultados encontrados nos municípios do RN com os paranaenses, observaram que os primeiros seguiam mais endividados.

Linhares, Penna e Borges (2013) e Borges et al. (2013) questionaram os efeitos da LRF sobre o endividamento. No caso do primeiro, o 
questionamento se restringiu aos municípios piauienses, tendo o estudo sugerido redução entre 0,0792 e 0,0669 sobre os municípios estudados. Isto é, o impacto da LRF perante esses municípios fez com que a proporção da receita corrente líquida necessária para cobrir as dívidas se reduzisse em, aproximadamente, $7 \%$. Em relação ao segundo, a pesquisa envolveu os estados, sendo que $70 \%$ deles após uma década de LRF foram considerados com baixo nível de endividamento, o que confirmou o impacto positivo da lei para o controle do endividamento estadual.

Gerigk, Ribeiro e Santos (2014) buscaram verificar o padrão de endividamento dos estados brasileiros da região sul e a sua dinâmica após o advento da LRF, a partir da definição de índices-padrão. De acordo com os autores, inexiste no Rio Grande do Sul, no Paraná e em Santa Catarina um padrão de endividamento e que o controle restou prejudicado pelo crescimento da dívida e obtenção de novos empréstimos. Em sentido oposto, Rodrigues (2016) encontrou grau de endividamento semelhante em estados brasileiros, com base em amostra colhida no período de 2000 a 2013, exceto quanto aos Estados do Amapá, Rio Grande do Norte e Distrito Federal.

Miranda et al. (2019) avaliaram a qualidade da gestão fiscal dos estados brasileiros, no período compreendido entre 2011 e 2015 . Utilizando como pressuposto a metodologia do Índice Firjan de Gestão Fiscal (IFGF), os estados foram classificados em gestão fiscal em dificuldade $(85,2 \%)$, crítica $(7,4 \%)$ e boa $(7,4 \%)$. Os resultados apontados evidenciaram que a região com melhor desempenho foi a Norte e com pior, a Sul. Identificou-se como principal causa o elevado desembolso com juros e amortização da dívida, o que estaria prejudicando a liquidez e a condição financeira dos estados.

Portanto, inquestionável considerar a LRF como "freio" do endividamento estatal. A continuação, os pesquisadores passaram a indagar-se acerca dos fatores que poderiam contribuir em maior ou menor propor- 
ção como limitadores do endividamento governamental. Neste sentido, os estudos também são variados e despertaram atenção pela utilização de indicadores fiscais e contábeis.

Em pesquisa realizada por Macedo e Corbari (2009), buscou-se o endividamento governamental com variáveis do tipo: estrutura de capital, liquidez, grau de dependência financeira com outro ente da federação, despesas com pessoal, despesas com investimento e endividamento defasado. Os resultados revelaram que, ao longo do período analisado (1998 a 2006), houve mudança no padrão de endividamento por meio das variáveis endividamento defasado e estrutura de capital. De acordo com Cândido Júnior (2009), os gastos com estrutura e investimentos são capazes de contribuir para o crescimento econômico, pois servem de insumo para o setor privado, melhorando o retorno da administração púbica a partir da quitação dos tributos.

Carvalho, Oliveira e Santiago (2010) realizaram pesquisa sobre o comportamento do endividamento público dos estados nordestinos, com base nas seguintes variáveis: endividamento de curto e longo prazo mensuradas a partir do montante de restos a pagar, receitas correntes arrecadadas e total da dívida. Concluíram que tanto a dívida de curto (restos a pagar), como a de longo prazo (empréstimos/financiamentos) foram afetadas pela LRF, exceto no que se refere aos estados da Bahia e Pernambuco.

Gorôncio e Teixeira (2010) também comparam os efeitos da LRF sobre o endividamento público em período anterior à existência da lei (1996 a 2000) e em anos seguintes a sua promulgação (2000 a 2008), mediante conjunto de indicadores (dívida financeira/receita líquida real, dívida consolidada líquida/receita corrente líquida). Embora os resultados não tenham se mostrado significantes quanto ao impacto da LRF sobre o endividamento, variáveis testadas como taxa Selic e período eleitoral comprovaram impacto na evolução do endividamento, contribuindo para a sua elevação. 
Ordonez e Crozatti (2013) procuraram identificar os fatores contábeis de maior impacto na diminuição do endividamento dos municípios brasileiros, utilizando dados referentes ao período de 1999 a 2010. A variável dependente utilizada foi o indicador DCL/RCL e as variáveis independentes foram ativo financeiro, passivo financeiro e receita corrente líquida. Os resultados indicaram que a receita corrente líquida é o fator que mais influencia na diminuição do indicador de endividamento dos municípios.

Ferreira et al. (2013) analisaram relação entre variáveis fiscais e endividamento dos estados, utilizando dados de período compreendido entre 2000 e 2010, referentes a todos os 26 estados e o Distrito Federal. Empregaram como variável dependente o coeficiente Dívida Consolidada Líquida e Receita Corrente Líquida e como variáveis independentes receita tributária, despesa com investimento, despesa com pessoal e transferências correntes. Evidências indicaram que o controle das despesas com pessoal e aumento das transferências correntes pode influenciar fortemente na diminuição do endividamento público.

Por sua vez, estudo de Gerigk, Ribeiro e Santos (2014) objetivou determinar um padrão no endividamento a partir de diversos indicadores (endividamento de curto prazo, de longo prazo, por operações de crédito interna e por operações de crédito externas, pagamento de juros da dívida, amortização das dívidas e dívida consolidada líquida). A pesquisa concluiu pela inexistência de um padrão de endividamento para os estados da região sul analisados e que o comportamento entre eles seria divergente.

Baseados na mesma premissa de comparar indicadores com o comportamento da dívida pública (dívida líquida do setor público, dívida bruta do governo geral - BACEN e dívida bruta do governo geral - FMI), Athayde e Vianna (2015) propuseram o exame do PIB e do superávit primário. Os resultados sugerem que a dívida bruta do governo geral, calculada pelo Banco Central do Brasil, é o melhor indicador, dentre os três pesquisados, 
para a medição do desempenho fiscal brasileiro nos últimos anos.

Costa, Raupp e Tezza (2018) sugeriram proposta de mensuração do endividamento público para os municípios brasileiros a partir do exame de 34 variáveis baseadas em três dimensões (capacidade financeira, relação Estado-sociedade e dependência de terceiros). O exame apontou que os municípios brasileiros possuem uma faceta multidimensional, razão pela qual devem ser analisados com base em modelo que considere as correlações entre indicadores sociais e de resultado.

Ademais, o controle dos gastos públicos no período que antecede às eleições não é algo novo na legislação brasileira, a exemplo da Lei Eleitoral (Lei 9.504/97, art. 73) (BRASIL, 1997) e da LRF (arts. 21, § único; 23, $\S 4^{\text {o }} ; 31, \S 3^{\text {o }} ; 38$ e 42) (BRASIL, 2000). Tal preocupação advém do histórico dos administradores públicos brasileiros de se valerem dos recursos públicos para influenciarem no processo eleitoral (BARTOLLUZZIO; ANJOS, 2020).

Fora do país, a associação entre eleição, gasto público (investimentos) e manipulação da vontade do eleitor tampouco é recente. Estudos realizados por Nordhaus (1975), Rogoff (1990), Rogoff e Sibert (1988) identificaram comportamento cíclico por parte dos agentes públicos em elevar investimentos públicos antes das eleições e diminuí-los passado o pleito. Chegaram a denominá-lo de teoria do ciclo político-orçamentário, por meio do qual se observou uma forte correlação entre endividamento e despesas com investimentos. Autores como Gonçalves e Fenólio (2007), Queiroz e Silva (2011), Brender e Drazen (2005) os descrevem como manipulações orçamentárias, geralmente por meio de transferências governamentais às vésperas das eleições, ocorrendo a desaceleração dos investimentos no ano posterior. 


\section{METODOLOGIA}

A presente pesquisa se classifica como descritiva pelos seus objetivos (GIL, 2008), documental quanto aos procedimentos (LAKATOS; MARCONI, 2007) e quantitativa quanto à abordagem (MATTAR, 2001).

$\mathrm{O}$ exame documental teve por base a legislação vigente, documentos oficiais, demonstrações contábeis e relatórios publicados pelos estados e pela Secretaria do Tesouro Nacional (STN). Os dados foram obtidos junto ao Sistema de Informações Contábeis (Sincofi) disponibilizado pela STN, junto ao site do mesmo ${ }^{5}$, Federação das Indústrias do Rio de Janeiro (Firjan) e pelo site Tesouro Transparente ${ }^{6}$, durante o período de julho a agosto de 2019.

No que se refere ao aspecto quantitativo, utilizou-se o Software Gnu Regression, Econometrics and Time-series Library (GRETL) para análise e tratamento dos dados, tendo por base a regressão linear múltipla em dados de corte transversal (Cross-Section) caracterizado por amostra de dados extraídos em um lapso temporal.

A população consistiu nos 26 estados e o Distrito Federal que tiveram a metodologia de cálculo dos juros alterada, tendo por base o ano de 2016 . A escolha do exercício se deve em razão do aumento do endividamento público, face ao recrudescimento da crise fiscal que assola o país desde 2008 e que levou com que a União propusesse alteração da legislação vigente (LC 156/2016) para alteração da métrica de cálculo da contabilização dos juros da dívida dos entes subnacionais (MIRANDA et al., 2018).

Com base na revisão da literatura, selecionou-se o seguinte conjunto de variáveis para avaliação do equilíbrio fiscal dos entes federados: endividamento, despesa com pessoal, disponibilidade de caixa (liquidez) e despesa com investimentos. Como variável dependente, utilizou-se o índice de endividamento previsto na LRF (DCL/RCL) e como variáveis

$5 \quad$ Disponível em: www.stn.gov.br

6 Disponível em: www.tesourotransparente.gov.br 
independentes foram adotados os indicadores selecionados a partir dos estudos citados anteriormente, num total de três variáveis selecionadas.

A tabela a seguir demonstra cada variável, seu cálculo e a relação esperada com a variável dependente.

Tabela 1: Resumo das variáveis

\begin{tabular}{c|c|c}
\hline Indicador & Fórmula & Tipo \\
\hline Endividamento (END) & DCL/RCL & DEPENDENTE \\
\hline Despesa com pessoal (DPES) & Despesa com pessoal/RCL & Independente \\
\hline Liquidez (LIQ) & Caixa - RAP/RCL & Independente \\
\hline Despesa com investimento (INV) & Despesa com investimento/RCL & Independente \\
\hline
\end{tabular}

Legenda: Restos a pagar processados (RAP), Receita corrente liquida (RCL), Despesa Corrente Liquida (DCL).

Fonte: Elaborada pelos autores (2019).

Com base na Tabela 1, tem-se que o endividamento é uma variável estoque e indica a proporção da Receita Corrente Líquida (RCL) necessária para se cobrir as dívidas em que se incorreu até então. A liquidez leva em consideração a parcela das obrigações que podem ser saldadas com recursos próprios disponíveis, deduzindo-se os Restos a Pagar Processados (RAP), ou seja, aqueles cujos bens e serviços já foram entregues e resta, somente, o pagamento efetivo.

A despesa com pessoal indica a parcela da receita corrente líquida comprometida com gastos de pessoal, nos moldes das despesas enumeradas pela LRF (art. 18), do tipo vencimento e vantagens fixas, pensões, reformas, aposentadorias e terceirização. $\mathrm{O}$ investimento busca captar se os dispêndios realizados vêm ampliando o endividamento estadual, devido serem a principal fonte das despesas de capital, responsáveis pela infraestrutura pública, a exemplo de portos, aeroportos, estradas, hospitais etc.

A partir do presente arcabouço foi possível construir as seguintes hipóteses:

H0: os indicadores selecionados (despesa de pessoal, índice de li- 
quidez e despesa com investimento) não exercem influência sobre o endividamento público.

H1: os indicadores de despesa com pessoal e com investimentos atuam positivamente elevando os níveis de endividamento público, enquanto o de liquidez atua de forma contrária, diminuindo o endividamento observado.

Para verificar o comportamento das variáveis independentes sobre o endividamento, foi aplicada a técnica multivariada de regressão linear múltipla, tendo em vista que os dados analisados se constituem em seccionais (estados) e de caráter multivariado em razão da quantidade de variáveis explicativas utilizadas e por permitir descrever a relação matemática entre elas.

A técnica se mostra adequada de acordo com Mingoti (2005). Segundo o autor, possibilita ainda simplificar e facilitar a interpretação do fenômeno que está sendo estudado por meio da construção de índices ou variáveis alternativas que sintetizam a informação original dos dados.

Além disso, permite construir grupos de elementos amostrais que apresentem similaridade entre si, possibilitando a segmentação do conjunto de dados originais. Por último, permite investigar as relações de dependência entre as variáveis associadas ao fenômeno, comparar populações ou validar suposições por meio de testes de hipóteses.

A equação a seguir apresenta o modelo proposto para verificar os fatores determinantes da dívida pública.

$$
\mathrm{END}=\beta_{0}+\beta_{1} \text { DEPES }_{\mathrm{i}}+\beta_{2} \mathrm{LIQ}_{\mathrm{i}}+\beta_{3} \mathrm{INV}_{\mathrm{i}}+\varepsilon_{\mathrm{i}}
$$

Onde:

$E N D=$ endividamento do estado $i$;

$D E P E S=$ despesa com pessoal do estado $i$;

$L I Q=$ liquidez do estado $i$

$I N V=$ despesa com investimento do estado $i$;

$\varepsilon=$ termo de erro. 


\section{ANÁLISE E DISCUSSÃO DOS RESULTADOS}

Este trabalho tem por objetivo analisar o comportamento de conjunto de variáveis e sua influência no endividamento dos estados brasileiros no ano de 2016. Tem-se como pano de fundo a alteração na legislação sobre dívida pública aprovada (LC 156/2017) com a finalidade de auxiliar no reequilíbrio fiscal e alteração da métrica de cálculo da dívida dos entes subnacionais.

O exame do crescimento da dívida e os fatores que podem influenciá-la não são algo recente no país (CARVALHO; OLIVEIRA; SANTIAGO, 2010; COSTA; RAUPP; TEZZA, 2019; CROZATTI, 2013; FERREIRA et al., 2013; GORÔNCIO; TEIXEIRA, 2010; MACEDO; CORBARI, 2009; ORDONEZ; CROZATTI, 2017), tendo sido importantes em identificar que variáveis que poderiam impactar no endividamento e assim auxiliar no comportamento decisório dos gestores públicos.

Com base na revisão da literatura, foram selecionadas as seguintes variáveis: despesa com pessoal (Depes), liquidez (LIQ) e despesa com investimento (INV), cuja estatística descritiva se encontra na Tabela 2. Os dados são representativos de 26 estados e do DF, exceção efetuada em relação a inconsistências e falta de informações referente ao estado do Rio Grande do Norte (RN).

Tabela 2: Resumo da estatística descritiva das variáveis estudadas

\begin{tabular}{c|c|c|c|c|c}
\hline Variável & $\mathbf{N}^{\mathbf{0}}$ Obs & Média & Desvio Padrão & Mínimo & Máximo \\
\hline END & 27 & 0,696 & 0,6287 & 0,031 & 2,338 \\
\hline DEPES & 27 & 0,572 & 0,0887 & 0,441 & 0,780 \\
\hline LIQ & 26 & 0,144 & 0,2391 & $-0,419$ & 0,736 \\
\hline INV & 27 & 0,057 & 0,0254 & 0,018 & 0,111 \\
\hline
\end{tabular}

Fonte: Dados da Pesquisa (2019).

As dispersões encontradas nas variáveis, os valores mínimos e máximos se devem a heterogeneidade existente entre os diferentes estados do 
país que divergem em tamanho, PIB, número de habitantes etc. Embora tais atributos sejam capazes de explicar muito o comportamento financeiro observado, não justificam, por si, desajustes fiscais, principalmente porque os desequilíbrios observados, na sua maioria, não se convertem em garantias da promoção de bens e serviços à coletividade.

Analisando os resultados, nota-se que a variável dependente (END) apresentou valor médio de $69 \%$ da receita corrente líquida, com dispersão de $63 \%$ em torno da média populacional. No entanto, essa média se altera entre os estados, a exemplo do Rio de Janeiro, que apresentou o valor de $234 \%$, ficando acima do teto de 2.0 (ou $200 \%$ sobre a RCL) estabelecido pela LRF. O percentual médio evidencia um bom resultado relativo à ocorrência de equilíbrio fiscal da dívida consolidada abaixo dos patamares definidos em lei, situação considerada favorável, muito embora não seja possível avaliar acerca do destino dado aos recursos captados.

No que se refere aos gastos com pessoal (Depes), a cifra chegou ao percentual de $57 \%$ da receita corrente líquida (RCL), com dispersão de $8 \%$ em torno da média populacional, o que demonstra a existência de unidades federadas com percentual inferior a $50 \%$ e outros, como é o caso de Minas Gerais, com percentual que chegou a 78\% da RCL. Considerando que o limite estabelecido pela LRF é de $60 \%$ para estados e municípios, a situação mineira não é favorável, visto que tanto o indicador de endividamento $(2,338)$ quanto o de despesa com pessoal $(0,780)$ extrapolaram o limite permitido.

No que se refere ao índice de liquidez (LIQ), ressalta-se que o valor mínimo apresentou sinal negativo $(-0,419)$, sendo explicado pela metodologia de cálculo da variável que considera a disponibilidade de caixa e restos a pagar, de forma que os restos a pagar podem ser superiores à disponibilidade de caixa. Esse valor ocorre no estado do Rio Grande do Sul, cujo valor é explicado pela diferença entre o volume de restos a pagar processados e os recursos em caixa deixados em 2016, que representou 
42\% da RCL, ou seja, R \$14,5 bilhões em despesas postergadas para 2017 , sem a devida cobertura. Ainda, ao analisar o valor máximo dessa variável $(0,736)$, o destaque positivo vai para o Maranhão, com $73,6 \%$, cujos recursos de caixa foram considerados suficientes para cobrir as despesas postergadas e ainda resultaram em crédito que supera $60 \%$ da RCL.

A variável de liquidez apresenta outra importante conclusão válida também para as despesas com investimentos. Tanto a liquidez $(0,144)$ quanto a despesa com investimentos $(0,057)$ possuem as menores médias evidenciadas. Isso demonstra deficiência na política financeira dos entes analisados, além de que o nível de investimento em despesa de capital é o mais desfavorável dentre as variáveis selecionadas.

$\mathrm{O}$ indicador relativo à despesa com investimento (INV) apresentou um valor médio baixo, com dispersão de $2 \%$ em torno da média populacional, fato que pode ser explicado pela forte retração existente no ano em estudo. Apenas três estados investiram mais que 10\% da RCL em 2016: Ceará, Piauí e Bahia. O Rio Grande do Sul foi o ente federado que menos investiu, apenas 1,8\% da sua RCL. Importa destacar que desde 2014 esse percentual não ultrapassa $2 \%$ da RCL, o que pode ser considerado preocupante, visto as carências existentes no país por obras de infraestrutura.

Com base nas variáveis selecionadas, realizou-se o teste $\mathrm{F}$ de significância, cujo objetivo é analisar a variância entre conjuntos de dados diferentes e compará-los, utilizando o teste de hipóteses. A aplicação do teste demonstrou significância estatística ao nível de 1\%, rejeitando-se a hipótese nula de que todos os coeficientes estimados seriam iguais à zero. O resultado demonstrou que existe influência significativa das variáveis independentes sobre a dependente, logo, os coeficientes de despesa com pessoal, de investimentos e liquidez, de alguma forma, interferem no endividamento público.

Por sua vez, o R2 demonstrou que as variáveis independentes explicam $61,20 \%$ do endividamento (END), resultado considerado satisfatório mesmo considerando somente três variáveis para estudo. Este percentual 
indica quanto o modelo consegue explicar os valores observados. Nesse sentido, quanto maior essa porcentagem, melhor e mais explicativa se torna a equação proposta.

O modelo de regressão sugerido consegue explicar o endividamento a partir das variáveis independentes e permitiu a verificação de alguns pressupostos: ausência de colinearidade e autocorrelação.

O pressuposto da ausência de colinearidade foi verificado pelo teste Variance Inflation Factor (VIF). O teste foi escolhido para verificar se as variáveis independentes possuíam relação linear entre si, algo que pode prejudicar os resultados do modelo. $\mathrm{O}$ teste indicou que as três variáveis não estão relacionadas, fato verificado através dos valores obtidos, Depes $=1,200, \mathrm{LIQ}=1,231$ e INV $=1,032$. Valores maiores que 10,0 podem indicar anomalias no exame da colinearidade.

Quadro 1: Fatores de Inflacionamento de Variância (VIF)

Valor mínimo possível $=1,0$

Valores $>10,0$ podem iniciar um problema de colinearidade

Depes 1,200

LIQ 1,231

INV 1,032

Fonte: Elaborado pelos autores (2019).

Os testes de Breusch-Pagan e White indicaram a confirmação do pressuposto de ausência heterocedasticidade. Verificou-se ainda que a condição da normalidade dos resíduos foi atendida conforme teste no software, teste escolhido para verificar se existe relação entre os resíduos e as variáveis independentes. 
Gráfico 1: Normalidade dos resíduos

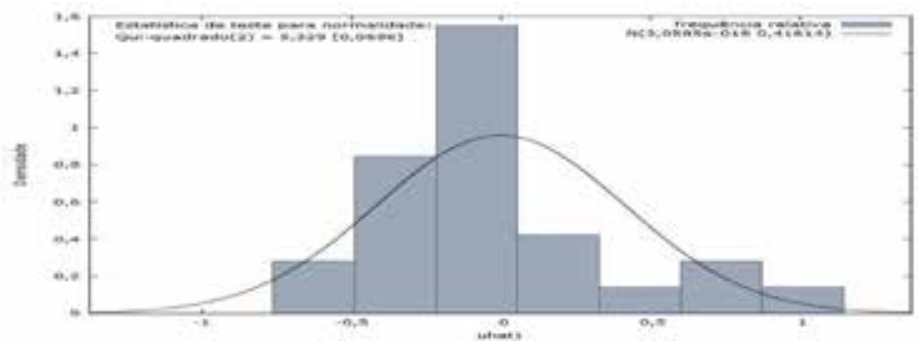

Fonte: Dados da Pesquisa (2019).

Teste de Breusch-Pagan para a heteroscedasticidade -

Hipótese nula: sem heteroscedasticidade

Estatística de teste: $\mathrm{LM}=0,168739$

com $\mathrm{p}$-valor $=\mathrm{P}($ Qui-quadrado $(3)>0,168739)=0,982471$

Teste de White para a heteroscedasticidade -

Hipótese nula: sem heteroscedasticidade

Estatística de teste: $\mathrm{LM}=4,67593$

com $\mathrm{p}$-valor $=\mathrm{P}($ Qui-quadrado $(9)>4,67593)=0,861594$

O pressuposto da ausência de autocorrelação não foi verificado devido ao modelo se tratar de dados de corte transversal, que consiste em uma amostra de uma unidade de análise tomada em um dado ponto no tempo e não de séries ao longo do tempo. A autocorrelação significa a relação de valores de uma mesma variável ordenados no tempo, com dados de séries temporais. 
Os resultados da aplicação das variáveis se encontram reproduzidos abaixo:

Tabela 3: Avaliação das variáveis

Modelo 1: MQO, usando as observações 1-27 (n=26)

\begin{tabular}{|c|c|c|c|c|c|}
\hline \multicolumn{6}{|c|}{ Observações ausentes ou incompletas foram ignoradas: 1} \\
\hline \multicolumn{6}{|c|}{ Variável dependente: END } \\
\hline & Coeficiente & Erro Padrão & razão-t & $p$-valor & \\
\hline const & $-0,676320$ & 0,641127 & $-1,055$ & 0,3029 & \\
\hline DEPES & 3,10432 & 1,03024 & 3,013 & 0,0064 & $* * *$ \\
\hline LIQ & $-1,18899$ & 0,386101 & $-3,079$ & 0,0055 & $* * *$ \\
\hline INV & $-3,44428$ & 3,27336 & $-1,052$ & 0,3041 & \\
\hline \multicolumn{2}{|c|}{ Média var. dependente } & 0,721814 & \multicolumn{2}{|c|}{ D.P. var. dependente } & 0,626693 \\
\hline \multicolumn{2}{|c|}{ Soma resíd. quadrados } & 3,809728 & \multicolumn{2}{|c|}{ E.P. da regressão } & 0,416136 \\
\hline \multicolumn{2}{|c|}{ R-quadrado } & 0,611989 & \multicolumn{2}{|c|}{ R-quadrado ajustado } & 0,559078 \\
\hline \multicolumn{2}{|c|}{$F(3,22)$} & 11,56647 & \multicolumn{2}{|c|}{ P-valor (F) } & 0,000093 \\
\hline
\end{tabular}

Fonte: Dados da pesquisa (2019).

Com base nos dados apresentados na Tabela 3, verificou-se que a variável despesa com pessoal (Depes) apresentou influência positiva $(3,10432)$ e significante na ordem de $p$-valor 0,0064 ao nível de $1 \%$. Isso significa que quanto maior a despesa com pessoal, maior o endividamento público, ou seja, um aumento de uma unidade nas despesas com pessoal gera um aumento de 3,10 no endividamento, validando assim os estudos de Ferreira et al. (2013) acerca do impacto das despesas com pessoal sobre o endividamento estatal.

Logo, pode-se concluir que o gasto com pessoal é um dos fatores determinantes da dívida pública, o que reforça a necessidade de os governos estaduais, além de respeitarem os limites impostos pela LRF, manterem controle efetivo das modalidades das despesas nele incluídas (vantagens, gratificações, horas extras, cargos comissionados, terceirização de 
mão-de-obra etc.). Esse resultado valida, portanto, a expectativa teórica contida na hipótese (H1) de que os gastos de pessoal possuem reflexos sobre o endividamento e corrobora as evidências de Piccoli e Jerszurki (2018) acerca da existência de relação entre o número de servidores efetivos e cargos comissionados com o crescimento do endividamento público.

A variável liquidez (LIQ) apresentou influência negativa sobre o endividamento, como esperado, eis que a existência de saldos de caixa não utilizados e não comprometidos poderão ser utilizados para cobrir eventuais dívidas constituídas. O resultado encontrado na ordem de $-1,18899$ e significante ao $p$-valor de 0,0055 ao nível de $1 \%$.

Isso indica que para o aumento de uma unidade da liquidez, o endividamento diminui em 1,18, demonstrado pelo sinal negativo do coeficiente apurado. Portanto, a relação inversa entre as variáveis confirma que o aumento da liquidez é capaz de diminuir a dívida pública, convalidando a assertiva contida na hipótese $\mathrm{H} 1$ sobre a liquidez.

O achado também valida a assertiva de Macedo e Corbari (2009) que consideraram esse indicador de gestão financeira como influenciador do endividamento. O resultado indica que a liquidez dos estados está relacionada à disponibilidade dos recursos próprios, o que afeta diretamente o nível de endividamento dos governos em estudo.

Comparando-se os coeficientes significantes entre si, percebe-se que, diferentemente do índice de despesa com pessoal $(3,10)$, a liquidez possui um impacto menor, muito embora igualmente expressivo $(1,18)$. O resultado revela, de certa forma, o comportamento dos governos estaduais no manuseio das finanças públicas e a preferência dos gestores públicos na produção dos seus indicadores, visto a importância dada aos gastos com pessoal quando comparados à formação de saldos financeiros positivos ao final dos exercícios.

Por fim, a variável despesa com investimento (INV) não apresentou significância estatística sobre o END. O percentual de investimento em relação à receita corrente líquida não exerceu influência sobre o endivi- 
damento público nesse ano específico ( $p$-valor de 0,3041), além de ter se mostrado negativo $(-3,44428)$.

$\mathrm{O}$ resultado à primeira vista parece contraditório, visto que no país há uma tendência maciça dos investimentos em relação à contratação de operações de crédito (internas e externas). Essa evidência diverge da conclusão de Linhares et al. (2013) e da expectativa teórica também contida em H1 para as despesas com investimento, razão pela qual carece de exame mais detalhado.

No que se refere ao sinal negativo do coeficiente $(-3,44428)$, a situação se explica a partir de dois motivos.

De antemão, há de se observar que os dados analisados não se referem a uma série histórica, mas se relacionam a um corte temporal, precisamente o exercício de 2016. Portanto, é possível concluir que os eventos ocorridos no ano analisado tenham influenciado negativamente na correlação entre endividamento e despesas com investimento, contradizendo estudos realizados anteriormente (BRENDER; DRAZEN, 2005; GONÇALVES; FENÓLIO, 2007; QUEIROZ; SILVA, 2011).

Tanto é assim que o exame do nível de investimento dos entes analisados permitiu constatar que apenas três estados investiram mais de $10 \%$ da RCL em 2016: Ceará, Piauí e Bahia, sendo o estado do Rio Grande do Sul aquele com menor nível de investimento, apenas 1,8\% da sua RCL, e desde 2014 o percentual não ultrapassa a 2\% da RCL. Igual situação pode ser mencionada por parte de Minas Gerais, dado que o percentual de investimento não chegou a 3\% da RCL em 2016 e no caso do Rio de Janeiro, por dois anos destinou 16,5\% da RCL para investimentos, e em 2016 esse percentual caiu para 5,4\% (FIRJAN, 2017).

Embora inegável a necessidade de investimento para os diversos estados brasileiros, infelizmente o comportamento das administrações estaduais observado é dado pela preferência às despesas com pessoal (Tabela $1=0,572)$ em comparação àquelas relacionadas à infraestrutura (Tabela $1=0,057)$. Esta conduta se justifica em razão de a despesa com pessoal 
no país possuir componentes de natureza obrigatória, não sendo permitido reduzir salários motivado pela diminuição da $\mathrm{RCL}$ - enquanto os investimentos, em sentido oposto, possuem natureza discricionária.

Por conseguinte, caso ocorram eventuais anomalias no montante da RCL apurada, há uma tendência entre os gestores públicos do país (independente da esfera de governo ou poder) de optar pelo contingenciamento dos investimentos ao invés de alterar os componentes da despesa com pessoal, mediante a diminuição de cargos e funções comissionadas e mão de obra terceirizada, sobretudo nos poderes legislativo e judiciário. E tanto é assim, que a menor dispersão observada entre as variáveis foi justamente a de investimento (INV = 0,0254), o que confirma o comportamento padrão entre os entes federados em utilizar cortes nas despesas com investimento como forma de equilibrar as contas públicas.

No que se refere à falta de significância ( $p$-valor 0,3041$)$ da variável INV, conforme dados constantes da Tabela 3, o resultado se explica em razão do ano analisado (2016), $2^{\circ}$ ano após o início da gestão dos governos eleitos que têm como justificativa o estudo de Lucena Júnior (2013). O autor explica que os níveis de investimento obedecem a um ciclo: consistem em despesa de longo prazo, exigem mais tempo de maturação e estão intrinsecamente relacionados aos períodos eleitorais do país.

Esse modus operandi traduz na verdade o que Nordhaus (1975), Rogoff (1990), Rogoff e Sibert (1988) identificaram como teoria do ciclo político-orçamentário, por meio do qual se observou a diminuição do nível de investimento público no primeiro ano pós-eleitoral e o aumento nos anos seguintes como forma de atrair os eleitores para as plataformas políticas dos gestores que se encontram no poder ou em prol de quem estes indicarem para lhes suceder. Autores como Gonçalves e Fenólio (2007), Queiroz e Silva (2011), Brender e Drazen (2005) os descrevem como manipulações orçamentárias que ocorrem por meio de transferências governamentais às vésperas das eleições e a desaceleração dos investimentos no ano posterior. 
Na presente situação, foi possível constatar que as gestões estaduais sofreram cortes nos investimentos também no segundo ano dos mandatos dos governadores (ano de 2016), ao invés de somente no primeiro ano após a eleição (ano de 2015). Tal evidência contradiz em parte a assertiva teórica constante da hipótese $\mathrm{H} 1$, no tocante à influência dos investimentos sobre o endividamento público no ano analisado, portanto, no ano seguinte ao pleito eleitoral.

\section{CONCLUSÕES}

O objetivo da pesquisa consistiu em identificar as variáveis que possuem maior capacidade de impacto perante o endividamento estatal brasileiro, dado ser inegável o crescimento do endividamento público e nem sempre os gestores constituírem esses passivos mediante exame criterioso das necessidades coletivas. Entende-se que o presente trabalho pode contribuir para o planejamento fiscal e tomada de decisão, face a confirmação do impacto das variáveis encontradas sobre o endividamento público, além de servir como instrumento para fiscalização da situação fiscal por parte da sociedade.

O estudo foi realizado tomando como base todos os estados brasileiros e o DF, tendo como referência o exercício de 2016, visto que nesse ano houve alteração da legislação sobre reequilíbrio fiscal (Brasil, 2016). Para atender ao objetivo consignado acima, foram selecionadas três variáveis com base na revisão da literatura, sendo a variável de resposta o endividamento (END) calculado pelo coeficiente entre a Receita Corrente Líquida (RCL) e Dívida Consolidada Líquida (DCL) e como variáveis independentes a despesa com pessoal (Depes), liquidez (LIQ) e despesa com investimento (INV).

De antemão, constatou-se a existência de influência significativa das variáveis independentes sobre a dependente $($ Depes $=p$-valor $0,0064 \mathrm{e}$ 
LIQ $=$ p-valor 0,0055$)$, o que permitiu rejeitar a hipótese nula de que todos os coeficientes estimados seriam iguais a zero.

Concernente a hipótese $\mathrm{H} 1$ - de que haveria influência positiva das despesas com pessoal e investimentos, e negativa da liquidez sobre o grau de endividamento público - os resultados permitiram observar que o dispêndio com pessoal é capaz de influenciar o endividamento público mais que proporcional ao aumento dessa modalidade de despesa (coeficiente de 3,10432). Em sentido oposto, o aumento dos níveis de liquidez é capaz de diminuir a dívida pública, também mais que proporcional (coeficiente de $-1,18899$ ) ao crescimento da dívida pública, porém em patamar inferior às despesas com pessoal. Esses resultados validaram as expectativas teóricas estabelecidas na primeira parte da hipótese $\mathrm{H} 1$.

Por fim, a terceira e última variável - despesa com investimento (INV) - permitiu concluir que esta modalidade de dispêndio não exerce influência sobre o endividamento ( $p$-valor 0,3041 ), pelo menos no ano em que a pesquisa foi realizada (exercício de 2016). Essa constatação contrariou a parte final da hipótese $\mathrm{H} 1$ de que a ocorrência de uma maior predisposição estatal em elevar o investimento público (gastos com a construção de escolas, pontes, viadutos, portos, aeroportos etc.) poderia repercutir diretamente na elevação dos patamares das obrigações contraídas.

Lucena Júnior (2013), com base nos estudos sobre a teoria do ciclo político-orçamentário (NORDHAUS, 1975; ROGOFF, 1990; ROGOFF; SIBERT, 1988), explicou a questão. De acordo com o autor, as despesas com investimento possuem uma forte conotação política, sendo bastante influenciada pelos chamados ciclos políticos.

Isso significa que as administrações públicas seriam mais suscetíveis a incrementos de despesas com investimento no período que antecede aos pleitos eleitorais, e redução no ano seguinte, no intuito de manipular o voto do eleitor (Brender; Drazen, 2005; Gonçalves; Fenólio, 2007; Queiroz; Silva, 2011;). No presente caso, a pesquisa constatou que a situação ocorreu, porém no $2^{\circ}$ ano de mandato dos governadores, conforme coefi- 
ciente apurado $(-3,44428)$, devendo-se destacar que não houve análise do ano seguinte ao pleito eleitoral (exercício de 2015).

Como limitação do trabalho é possível citar a indisponibilidade de dados do estado do Rio Grande do Norte no ano de 2016, podendo ter causado algum tipo distorção nos resultados apurados. Contudo, como era intenção identificar variáveis capazes de influenciar no endividamento, consideraram-se adequadas as conclusões obtidas.

Ressalta-se que as evidências apresentadas se referem a uma aplicação nos estados brasileiros, de forma que não se pode generalizar as conclusões estabelecidas na pesquisa para os demais entes federativos (municípios). Além disso, destaca-se que o estudo não esgotou os fatores determinantes do endividamento público, dado que o nível de explicação do modelo chegou a $62,66 \%$, restando ainda outros constructos capazes de predizer os $37,34 \%$ residuais. Portanto, sugere-se para pesquisas futuras a utilização de outras variáveis que possam ampliar o universo preditivo do endividamento público, além da inclusão de amostra representativa dos municípios, de modo a comparar o comportamento de entes federativos distintos.

\section{REFERÊNCIAS}

ARAÚJO, J. A.; MONTEIRO, V. B.; CAVAlCANTE, C. A. Influência dos gastos públicos no crescimento econômico dos Municípios do Ceará. In: CARVALHO, E. B. S.; OLIVEIRA, J. L.; TROMPIERI NETO, N.; MEDEIROS, C. N.; SOUSA, F. J. (org.). Economia do Ceará em Debate, Fortaleza, p. 176-200, 2010. Disponível em: https://bityli.com/ YER9N. Acesso em: 19 jan. 2020.

ATHAYDE, D. R.; VIANNA, A. C. Dívida pública brasileira: uma análise comparativa dos três principais indicadores de esforço fiscal do governo. 
Nova Economia, Belo Horizonte, v. 25, n. 2, p. 403-420, 2015. Disponível em: https://bityli.com/32PKL. Acesso em: 24 out. 2018.

BARTOLUZZIO, A. I. S. S; ANJOS, L. C. M. Ciclos políticos e gestão fiscal nos municípios brasileiros. Revista de Administração Contemporânea, Curitiba, v. 24, n. 2, p. 167-180, 2020.

BLANCHARD, O. Macroeconomia. 5. ed. Irvine: Pearson Universidade, 2011.

BRENDER, A.; DRAZEN, A. How do budget deficits and economic growth affect reelection prospects? Evidence from a large cross-section of countries. National Bureau of Economic Research, Cambridge, n. 11862, p. 1-33, 2005.

BORGES, G. F.; SILVA, C. M. D.; SILVA, K. A. T.; BENEDICTO, G. C.; ANTONIALLI, L. M. Endividamento dos estados brasileiros após uma década da LRF: uma análise com estatística multivariada. Revista FS, Teresina, v. 10, n. 4, 2013.

BRASIL. Lei no 4.320, de 17 de março de 1964. Estatui normas gerais de direito financeiro para elaboração e controle dos orçamentos e balanços da União, dos Estados, dos Municípios e do Distrito Federal. Diário Oficial da União, Brasília, DF, 23 mar. 1964.

BRASIL. [Constituição (1988)]. Constituição da República Federativa do Brasil. Brasília, DF: Senado Federal, 1988. Disponível em: https:// bityli.com/cqme8. Acesso em: 24 out. 2018.

BRASIL. Lei Complementar $\mathrm{n}^{\circ}$ 82, de 27 de março de 1995. Disciplina os limites das despesas com o funcionário público, na forma do art. 169 
da Constituição Federal (Lei Camata). Diário Oficial da União, Brasília, DF, 27 mar. 1995. Disponível em: https://bityli.com/zAmR0. Acesso em: 19 jan. 2020.

BRASIL. Lei $n^{\circ}$ 9.504, de 30 de setembro de 1997. Estabelece normas para as eleições. Diário Oficial da União, Brasília, DF, 30 set. 1997. Disponível em: https://bityli.com/CXWvy. Acesso em: 18 jan. 2020.

BRASIL. Lei Complementar no 96, de 31 de maio de 1999. Disciplina os limites das despesas com pessoal, na forma do art. 169 da Constituição Federal. Diário Oficial da União, Brasília, DF, 31 maio 1999. Disponível em: https://bityli.com/6Xs8c. Acesso em: 19 jan. 2020.

BRASIL. Lei Complementar $n^{\circ} 101$, de 4 de maio de 2000. Estabelece normas de finanças públicas voltadas para a responsabilidade na gestão fiscal e dá outras providências. Diário Oficial da União, Brasília, DF, 4 maio 2000a. Disponível em: https://bityli.com/y2k4b. Acesso em: 18 ago. 2019.

BRASIL. Lei $n^{\circ} 10.028$, de 19 de outubro de 2000. Altera o Decreto-Lei no 2.848 , de 7 de dezembro de 1940 - Código Penal, a Lei ${ }^{\circ} 1.079$, de 10 de abril de 1950, e o Decreto-Lei no 201, de 27 de fevereiro de 1967. Diário Oficial da União, Brasília, DF, 19 out. 2000b. Disponível em: https://bityli.com/NBSFQ. Acesso em: 19 jan. 2020.

BRASIL. Resolução Senado Federal n ${ }^{\circ}$ 40, 21 de dezembro de 2001. Dispõe sobre os limites globais para o montante da dívida pública consolidada e da dívida pública mobiliária dos estados, do DF e dos municípios, em atendimento ao disposto no art. 52, VI e IX, da CF. Diário Oficial da União, Brasília, DF, 21 dez. 2001a. Disponível em: https:// bityli.com/0AVBo. Acesso em: 19 jan. 2020. 
BRASIL. Resolução Senado Federal no 43, 21 de dezembro de 2001. Dispõe sobre as operações de crédito interno e externo dos estados, do DF e dos municípios, inclusive concessão de garantias, seus limites e condições de autorização, e dá outras providências. Diário Oficial da União, Brasília, DF, 21 dez. 2001b. Disponível em: https://bityli.com/ qO1cW. Acesso em: 19 jan. 2020.

BRASIL. Emenda Constitucional n ${ }^{\circ}$ 95, de 15 de dezembro de 2016. Altera o Ato das Disposições Constitucionais Transitórias, para instituir o Novo Regime Fiscal, e dá outras providências. Diário Oficial da União, Brasília, DF, 15 dez. 2016a. Disponível em: https://bityli.com/BIjWk. Acesso em: 19 jan. 2020.

BRASIL. Lei Complementar $\mathrm{n}^{\circ} 156$, de 28 de dezembro de 2016. Estabelece o plano de auxílio aos estados e medidas de estímulo ao reequilíbrio fiscal. Diário Oficial da União, Brasília, DF, 28 dez. 2016b.

BRASIL. Lei Complementar $\mathrm{n}^{\circ}$ 159, de 19 de maio de 2017. Institui o Regime de Recuperação Fiscal dos Estados e do Distrito Federal e altera as Leis Complementares no 101, de 4 de maio de 2000, e no 156, de 28 de dezembro de 2016c. Diário Oficial da União, Brasília, DF, 19 maio 2017.

CALDEIRA, A. A.; WILBERT, M. D.; MOREIRA, T. B. S.; SERRANO, A. L. M. Sustentabilidade da dívida estadual brasileira: uma análise da relação dívida líquida e resultado primário. Revista de Administração Pública, Rio de Janeiro, v. 50, n. 2, p. 285-306, 2016.

CÂNDIDO JÚNIOR, J. O. Os gastos públicos no Brasil são produtivos? Planejamento e Políticas Públicas, Brasília, DF, n. 23, p. 233-260, 2009. CARVALHO, J. R. M.; OLIVEIRA, G. F.; SANTIAGO, J. S. Dívida pú- 
blica: um estudo de indicadores dos estados nordestinos. Revista Universo Contábil, Blumenau, v. 6, n. 2, p. 82-100, 2010.

COSTA, C. B.; TEZZA, R.; CANCELLIER, E. L. P. L.; RAUPP, F. M. Mensuração do endividamento público: uma análise da literatura. Administração de Empresa em Revistas, Curitiba, v. 18, n. 19, p. 73-89, 2018. Disponível em: https://bityli.com/5ste4. Acesso em: 17 ago. 2019.

FERREIRA, A. C.; ARAÚJO, J. M.; BARROS, R. G.; VIANA, R. F. C.; REIS, F. A. Fatores determinantes do endividamento dos estados brasileiros: uma análise de 2000 a 2010. Saber Nordeste, Parnaíba, v. 8 , p. 1-16, 2013.

FIRJAN. A situação fiscal dos estados brasileiros. Rio de Janeiro: Firjan, 2016.

GALDINO, J. A.; MOURA, J. B.; CUNHA, E. L. Efeitos do enfoque patrimonial na dívida pública flutuante: um estudo de caso em uma fundação pública do norte do Brasil. Revista Contemporânea de Contabilidade, Florianópolis, v. 11, n. 23, p. 31-52, 2014.

GERIGK, W; RIBEIRO, F; SANTOS, L. O padrão de endividamento dos estados da região sul e a sua dinâmica após a edição da lei de responsabilidade fiscal por meio de índices-padrão. Revista Catarinense da Ciência Contábil, Florianópolis, v. 13, n. 39, p. 34-48, 2014. Disponível em: https://bityli.com/izKX4. Acesso em: 13 ago. 2019.

GIAMBIAGI, F.; ALÉM, A. C. Finanças públicas: teoria e prática no Brasil. 6. ed. Rio de Janeiro: Elsevier, 2016. 
GIL, A. C. Como elaborar projetos de pesquisa. 4. ed. São Paulo: Atlas, 2008.

GONÇALVES, C. E. S.; FENÓLIO, F. R. Ciclos eleitorais e política monetária: evidência para o Brasil. Pesquisa e planejamento econômico, Brasília, DF, v. 37, n. 3, p. 465-488, 2007. Disponível em: https://bityli. com/iyRFw. Acesso em: 19 jan. 2020.

GORÔNCIO, E. A.; TEIXEIRA, A. C. C. O endividamento dos estados brasileiros após a lei de responsabilidade fiscal - LRF. In: ENCONTRO DA ANPAD, 34, 2010, Rio de Janeiro. Anais [...]. Rio de Janeiro: Anpad, 2010. p. 1-17 Disponível em: https://bit.ly/33wzpC8. Acesso em: 19 jan. 2020.

KOHAMA, H. Contabilidade pública: teoria e prática. 14. ed. São Paulo: Atlas, 2014.

LAKATOS, E. M.; MARCONI, M. A. Fundamentos de metodologia científica. 6. ed. São Paulo: Atlas, 2007.

LIMA, S. C. Desempenho fiscal da dívida dos grandes municípios brasileiros. 2011. Tese (Doutorado em Contabilidade) - Faculdade de Economia, Administração e Contabilidade, Universidade de São Paulo, São Paulo, 2011.

LINHARES, F.; PENNA, C.; BORGES, G. Os efeitos da Lei de Responsabilidade Fiscal no endividamento dos municípios do Piaú́. Revista de Administração Pública, Rio de Janeiro v. 47, n. 6, 1359-1373, 2013. Disponível em: https://bityli.com/r7dh7. Acesso em: 8 ago. 2019.

LUCENA JÚNIOR, B. M. Uma análise dos investimentos públicos, dívida consolidada líquida e receita corrente líquida dos estados 
brasileiros no ciclo político de 2002-2010. 2013. Dissertação (Mestrado Profissional) - Universidade Federal do Ceará, Fortaleza, 2013.

MACEDO, J. J.; CORBARI, E. C. Os determinantes financeiros do endividamento dos municípios brasileiros: uma análise econométrica. In: ENCONTRO NACIONAL DA ASSOCIAÇÃO NACIONAL DE PÓSGRADUAÇÃO E PESQUISA EM ADMINISTRAÇÃO, 33., 2009, São Paulo. Anais [...]. São Paulo: Anpad, 2009. p. 1-55.

MATTAR, F. N. Pesquisa de marketing. 3. ed. São Paulo: Atlas, 2001.

MELLO, G. R; SLOMSKI, V. Fatores que influenciam o endividamento dos estados brasileiros. Revista de Contabilidade e Organizações, São Paulo, v. 3, n. 7, p. 78-92, 2009. Disponível em: https://bityli.com/Kvckd. Acesso em: 17 ago. 2019.

MELLO, G. R.; DALCHIAVON, E. C. A Lei de Responsabilidade Fiscal (LRF) e o impacto sobre o endividamento dos municípios potiguares. Revista Contemporânea de Economia e Gestão, Fortaleza, v. 10, n. 2, 2012.

MINGOTI, S. A. Análise de dados através de métodos de estatística multivariada: uma abordagem aplicada. Belo Horizonte: Editora UFMG, 2005.

MIRANDA, W. L. L. C.; ARAÚJO, R. J. R.; LEITE, Í. F; NOBRE; C. J. F. Avaliação da gestão fiscal nos estados brasileiros: análise no quinquênio 2011 a 2015. Revista Mineira de Contabilidade, Belo Horizonte, v. 19, n. 1, art. 5, p. 55-67, 2018. Disponível em: https://bityli.com/jY38x. Acesso em: 7 jul. 2019.

MUSGRAVE, R. A. Teoria das finanças públicas. São Paulo: Atlas, 1973. 
NORDHAUS, W. The political business cycle. Review of economic studies, Londres, v. 42, n. 2, p. 90-169, 1975.

OLIVEIRA, F. A. Economia e política das finanças públicas no Brasil. Campinas: Hucitec, 2012.

ORDONEZ, A. R. N; CROZATTI, J. Razões da diminuição do endividamento dos municípios brasileiros: o que dizem os balanços públicos de 1999 e 2010. Revista Gestão \& Políticas Públicas, v. 5, n. 2, p. 196-226, 2017. Disponível em: https://bityli.com/4YG29. Acesso em: 10 ago. 2019.

PEREIRA, P. T.; AFONSO, A.; ARCANJO, M.; SANTOS, J. C. G. Economia e finanças Públicas. Lisboa: Escolar, 2016.

PICCOLI, M. R.; JERSZURKI, A. Endividamento público: uma análise em duas associações de municípios catarinenses. Revista de Gestão e Contabilidade da UFPI, Floriano, v. 5, n. 1, p. 85-99, 2018. Disponível em: https://bityli.com/i1MYm. Acesso em: 13 jul. 2019.

QUEIROZ, D. B.; SANTOS, D. D. T.; MORAIS, L. M. F.; SOUSA, R. G. Determinantes do endividamento público: um estudo nos estados brasileiros. In: USP Internacional Conference in Accounting, 18., 2018, São Paulo. Anais [...]. São Paulo: FEA, 2018. Disponível em https:// congressousp.fipecafi.org/anais/anais2018/ArtigosDownload/1005.pdf. Acesso em: 12 set. 2019.

QUEIROZ, M. C. L.; SILVA, A. B. Ciclos políticos orçamentários no estado do Ceará (1986-2006). Planejamento e Políticas Públicas, Brasília, DF, v. 2, n. 35, 2011.

REZENDE, F. Finanças públicas. 2. ed. São Paulo: Atlas, 2001. 
RODRIGUES, M. G. D. Grau de endividamento: um estudo nos estados brasileiros. 2016. Trabalho de Conclusão de Curso (Graduação em Ciências Contábeis) - Centro de Ciências Sociais Aplicadas, Universidade Estadual da Paraíba, João Pessoa, 2016. Disponível: https://bityli.com/ XCf3e. Acesso: 19 jan. 2020.

ROGOFF, K. Equilibrium political budget cycles. American Economic Review, Nashville, v. 80, p. 21-36, 1990.

ROGOFF, K.; SIBERT, A. Elections and macroeconomic policy cycles. Review of Economic Studies, Londres, n. 55, p. 1-16, 1988.

SOARES, C. S.; CERETTA, P. S. A Lei de Responsabilidade Fiscal e o comportamento do endividamento dos Estados brasileiros: uma análise de dados em painel de 2000 a 2010. In: ENCONTRO BRASILEIRO DE ADMINISTRAÇÃO PÚBLICA E GOVERNO, 2012, Salvador. Anais [...]. Salvador: Anpad, 2012. p. 1-16. Disponível em: https://bit. ly/3g3Km3q. Acesso em: 19 jan. 2020.

TABOSA, F. J. S.; FERREIRA, R. T.; SIMONASSI, A. G. Reação fiscal ao aumento da dívida pública: uma análise para os estados brasileiros. In: ENCONTRO NACIONAL DE ECONOMIA, 39., 2011, Foz do Iguaçu. Anais [...]. Foz do Iguaçu: Anpec, 2011. p. 1-16.

VARGAS, N. C. A descentralização e as teorias do federalismo fiscal. Revista Ensaios FEE, Porto Alegre, v. 32, n. 1, p. 51-76, 2011. 